\title{
Entre el conflicto y el aislamiento: desarrollo, gobernabilidad y seguridad en las zonas fronterizas del norte y el sur de Chile a comienzos del siglo XXI
}

\author{
Between conflict and isolation: development, governance and security in the border \\ areas of northern and southern Chile early twenty-first century
}

Loreto Correa Vera ${ }^{1 *}$, Alejandro Salas Maturana ${ }^{1}$, Sergio Soza-Amigo², Viviana García Pinzón ${ }^{3}$

\begin{abstract}
RESUMEN
El estudio comprueba que en Chile predomina la visión de frontera como el límite territorial, limitándose a una acción/visión particularmente defensiva o de economía extractiva; acción/visión que ha limitado a las políticas públicas en el marco de la globalización y que pese a cambios administrativos, sigue siendo centralizada. De este modo, las regiones extremas entran en un debate colectivo asimétrico con sus pares a nivel nacional en una compleja inferioridad de condiciones.
\end{abstract}

Palabras clave: regiones extremas, gobernabilidad, desarrollo, seguridad, Chile.

\section{ABSTRACT}

The study found that in Chile border vision predominates as the territorial limit, limited to an action/particularly defensive or extractive economy vision, action/vision limited to public policy in the context of globalization, despite administrative change is centralized. Thus, the end regions asymmetric enter a collective discussion with their peers nationwide in a complex disadvantage. Key words: extreme regions, governability, development, security, Chile

\section{Resultados}

El desarrollo y población de las regiones extremas han estado postergados de la visión país. En ese marco, el aislamiento (Boisier, 2004) funciona como consecuencia del modelo económico de regionalismo abierto que exhibe Chile (Delamaza, 2009), más que por la distancia real, condición que se va expandiendo a otras regiones aún más cercanas. Esta investigación establece que el desarrollo nacional no ha definido, en el contexto de una discusión política inclusiva, estrategias permanentes de política pública para el establecimiento de un desarrollo territorial en las regiones de manera diferenciada (Correa, 2013).

¿Cómo es que pese a los incentivos, políticas sectoriales, planes y programas, o asignaciones especiales a causa de catástrofes naturales, cualquier monto público resulta insuficiente para sostener el crecimiento y fortalecer el aumento demográfico?
La respuesta está en la ausencia de una política pública integrada que fortalezca la gestión regional, la desconcentración del poder político a partir del empoderamiento de las élites regionales y la modernización del Estado en regiones territorialmente equipadas. En las Tablas 1 y 2 se sintetizan los datos y dimensiones de la invisibilidad de las regiones extremas del país.

\section{Dimensión 1: Gobernabilidad regional}

Tras caracterizar la política de desarrollo territorial en las zonas fronterizas del norte y sur del país se determinó un escaso peso político de las regiones extremas a nivel nacional, y aun menor influencia a nivel económico (Aroca y Soza-Amigo, 2012 y 2013) para definir estrategias de desarrollo satisfactorias para la población. La estructura multidimensional de las regiones fronterizas del norte y sur del país ha sido permanentemente

1 Academia Nacional de Estudios Políticos y Estratégicos, Av. Eliodoro Yáñez 2760, Providencia, Santiago, Chile.

2 Universidad de Magallanes. Punta Arenas, Chile.

3 Universidad Nacional de Colombia. Bogotá, Colombia.

* Autor por correspondencia: 1correa@anepe.cl 
Tabla 1. Total Indicadores Regiones Extremas 2006-2014.

\begin{tabular}{|c|c|c|c|c|}
\hline Indicador & Arica y Parinacota & Tendencia & $\begin{array}{c}\text { Magallanes y Antártica } \\
\text { Chilena }\end{array}$ & Tendencia \\
\hline $\begin{array}{l}\text { Propuestas Programas de } \\
\text { Gobierno }\end{array}$ & 21 & & 18 & \\
\hline Población Nacional & $1,30 \%$ & & $1 \%$ & \\
\hline Territorio Nacional & $2,23 \%$ & & $17,50 \%$ & \\
\hline Densidad de Población & 11,24 & & 1,14 & \\
\hline Presupuesto Regional & 2008-2014 & $\widehat{\mho}$ & 2008-2014 & $\widehat{\bigcup}$ \\
\hline FNDR & $2007-2011$ & $\widehat{U}$ & $2007-2011$ & 仓 \\
\hline $\begin{array}{l}\text { Iniciativas de } \\
\text { Inversión-Programas }\end{array}$ & $2008-2014$ & 仓 & $2008-2014$ & H \\
\hline $\begin{array}{l}\text { Iniciativas de Inversión } \\
\text { Proyectos }\end{array}$ & $2008-2014$ & & 2008-2014 & 仓 \\
\hline Proyectos y Programas & 89 & & 62 & \\
\hline Políticas Públicas Específicas & 4 & & 3 & \\
\hline $\begin{array}{l}\text { Dotación Personal Intendencias } \\
\text {-Planta }\end{array}$ & 2009-2014 & $\Leftrightarrow$ & 2009-2014 & $\Leftrightarrow$ \\
\hline $\begin{array}{l}\text { Dotación Personal } \\
\text { Intendencias- A Contrata }\end{array}$ & 2009-2014 & 仓 & 2009-2014 & $\Leftrightarrow$ \\
\hline $\begin{array}{l}\text { Dotación Personal Gobiernos } \\
\text { Regionales- Planta }\end{array}$ & 2009-2014 & 8 & 2009-2014 & 8 \\
\hline $\begin{array}{l}\text { Dotación Personal Gobiernos } \\
\text { Regionales-A Contrata }\end{array}$ & 2009-2014 & 仓 & 2009-2014 & $\widehat{U}$ \\
\hline Dotación Congreso-Senadores & 2014-2018 & $2^{*}$ & 2014-2018 & 2 \\
\hline Dotación Congreso-Diputados & 2014-2018 & 2 & 2014-2018 & 2 \\
\hline
\end{tabular}

* Nótese que la Región de Arica y Parinacota fue creada el 2008 sin senador que la representase, cargos cubiertos por los dos senadores de la Primera Región de Tarapacá.

Fuentes:

Tramitación de Proyectos, Senado de Chile.

Instituto Nacional de Estadísticas. Datos Regionales

Cuenta Pública Intendencia Región de Arica y Parinacota, Ministerio del Interior y Seguridad Pública (2010-2014).

Cuenta Pública Intendencia Región de Magallanes y la Antártica Chilena, Ministerio del Interior y Seguridad Pública (2010-2014).

Intendencia de Arica y Parinacota.

Intendencia de Magallanes y Antártica Chilena.

Gobierno Regional de Arica Parinacota.

Gobierno Regional de Magallanes y Antártica Chilena.

Elaboración propia.

ignorada por el Estado (García, 2014). Esto provoca una invisibilidad casi total de sus intereses, lo que se expresa cuantitativamente en el producto nacional (Soza-Amigo y Correa, 2014). Esto puede ser entendido desde dos perspectivas: por un lado como una acción deliberada por parte del poder político central del país, o bien, como la incapacidad central por atender a todas las regiones. No obstante, se concluye que desde 1990, cuando vuelve la democracia al país, el Estado chileno optó por mitigar la pobreza extrema que había. Por ello, la emergencia de accionar del Estado respecto de las regiones constituye un reparo nacional que surge cuando el primer proceso, el de la reducción de la pobreza en términos globales está concluido. Solo entonces se advierten las desigualdades y la invisibilidad de las regiones (Correa, 2013).

Desde una perspectiva nacional, la relación del Estado chileno con su propio territorio tiene matices. Al centrar la atención en las zonas extremas, se observó que si bien hay un trato especial en términos discursivos y fundamentalmente geopolíticos, este escasamente ha quedado plasmado en las políticas públicas regionales. La concentración 
Tabla 2. Proyectos y programas zonas extremas de Chile, Región XV Arica y Parinacota (2010-2014) y Región XII Magallanes y la Antártica Chilena.

\begin{tabular}{|c|c|c|c|c|c|c|c|c|}
\hline \multirow[b]{2}{*}{ Región } & \multicolumn{8}{|c|}{ Indicadores Regionales (Partidas presupuestarias expresadas en Cuenta Pública por el Intendente Regional) } \\
\hline & $\begin{array}{l}\text { Desarrollo } \\
\text { productivo }\end{array}$ & $\begin{array}{l}\text { Seguridad } \\
\text { ciudadana }\end{array}$ & $\begin{array}{l}\text { Infraest. y } \\
\text { conectividad }\end{array}$ & Salud pública & Educación & Agenda Social & Turismo & Total \\
\hline \multicolumn{9}{|l|}{ Arica y Parinacota } \\
\hline $\begin{array}{l}\mathrm{N}^{\circ} \text { total proyectos y } \\
\text { programas }\end{array}$ & 24 & 15 & 21 & 15 & 7 & 7 & 0 & 89 \\
\hline $\begin{array}{l}\mathrm{N}^{\circ} \text { de proyecto sin } \\
\text { monto asignado }\end{array}$ & 16 & 5 & 11 & 3 & 1 & 4 & 0 & 40 \\
\hline $\begin{array}{l}\mathrm{N}^{\circ} \text { de proyecto con } \\
\text { monto asignado }\end{array}$ & 8 & 10 & 10 & 12 & 6 & 3 & 0 & 49 \\
\hline $\begin{array}{l}\text { Montos expresados } \\
\text { en M\$ pesos }\end{array}$ & $\$ 68.166$ & $\$ 52.834$ & $\$ 289.995$ & $\$ 80.529$ & $\$ 203.769$ & $\$ 24.420$ & $\$ 0$ & $\$ 719.713$ \\
\hline $\begin{array}{l}\text { Montos expresados } \\
\text { en M\$ dólares } \\
\text { Magallanes y Antártica } \\
\text { Chilena }\end{array}$ & US \$ 1165 & US $\$ 0$ & US $\$ 0$ & US $\$ 0$ & US \$0 & US $\$ 0$ & US \$0 & US \$1.165 \\
\hline $\begin{array}{l}\mathrm{N}^{\circ} \text { total proyectos y } \\
\text { programas }\end{array}$ & 6 & 4 & 22 & 10 & 9 & 4 & 7 & 62 \\
\hline $\begin{array}{l}\mathrm{N}^{\circ} \text { de proyectos sin } \\
\text { monto asignado }\end{array}$ & 0 & 0 & 4 & 2 & 1 & 0 & 0 & 7 \\
\hline $\begin{array}{l}\mathrm{N}^{\circ} \text { de proyectos con } \\
\text { monto asignado }\end{array}$ & 6 & 4 & 18 & 8 & 8 & 4 & 7 & 55 \\
\hline $\begin{array}{l}\text { Montos expresados } \\
\text { en M\$ pesos }\end{array}$ & $\$ 10.802 .272$ & $\$ 338.091$ & $\$ 411.986 .800$ & \$11.181.135 & $\$ 153.270 .860$ & $\$ 84.171 .072$ & $\$ 15.254 .933$ & $\$ 687.005 .163$ \\
\hline $\begin{array}{l}\text { Montos expresados } \\
\text { en M\$ dólares }\end{array}$ & US $\$ 500.064$ & US $\$ 0$ & US $\$ 15$ & US $\$ 0$ & US $\$ 0$ & US $\$ 0$ & US $\$ 5.000$ & US $\$ 505.079$ \\
\hline
\end{tabular}

Fuente:

Cuenta Pública Intendencia Región de Arica y Parinacota, Ministerio del Interior y Seguridad Pública (20102014).

Cuenta Pública Intendencia Región de Magallanes y la Antártica Chilena, Ministerio del Interior y Seguridad Pública (2010-2014). Elaboración propia.

de servicios, actividades económicas y perfil político en el centro del país ha alcanzado límites que afectan negativamente el crecimiento de la nación. Las regiones extremas requieren de políticas públicas distintas del contexto nacional e incluso entre sí, porque son dependientes del centro productivo, localmente débil en su institucionalidad e internacionalmente permeable a amenazas externas.

A partir del análisis de coaliciones promotoras, la política de zonas extremas a pesar de tener cuatro décadas, exhibe características de un subsistema incipiente. En este contexto, la coalición de control político dominante está determinada por el Ejecutivo sin que, desde los actores regionales, se haya logrado consolidar una coalición opositora. Por ello, su dinámica exhibe cambios graduales y discretos motivados por factores externos propios del sistema.

En términos de desarrollo territorial y gobernabilidad a nivel subnacional se ha observado la condición de aislamiento de las regiones del extremo norte y sur de Chile, ha favorecido la consecución de manifestaciones de descontento, lo que no es sino muestra de la debilidad de las políticas públicas del Estado en esas zonas y de la falta de aplicación de programas que incidan en la creación de empleo (Correa, 2013).

\section{Dimensión 2: Desarrollo económico}

El análisis teórico de las zonas fronterizas demuestra que las márgenes de los Estados han dejado de ser un espacio que marca los límites entre soberanías en disputa, para ser espacios de convergencia de diversos actores, fenómenos y relaciones sociales (García, 2014). Este es el marco que o bien genera dinámicas económicas regionales propias que posicionan a estos territorios como pivotes para el desarrollo y la integración o por el contrario, dan lugar a una progresiva descomposición de la institucionalidad. 
Los estudios publicados por esta investigación dan cuenta de que el problema de fondo en Chile radica en la ausencia de modelo descentralizado de desarrollo sustentado en coaliciones promotoras regionales. Esto es resultado de un laisez faire originado por la estructura productiva regional y de un éxodo permanente. Todo lo anterior ha provocado una marginalización del potencial de agencia de los actores locales, generándose un continuo desapego regional y una ausencia de incentivos para un desarrollo endógeno, provocando carencia de desarrollo productivo y la instalación de fenómenos como la conmutación y desindustrialización local.

\section{Dimensión 3: Seguridad}

La situación del extremo norte del país experimenta progresivamente una absorción de los fenómenos de seguridad que hoy forman parte de las agendas de seguridad de países latinoamericanos. Las condiciones de inserción efectiva de estos territorios en el contexto nacional difieren estratégicamente de las políticas activas de los países vecinos que han fortalecido de manera activa el poblamiento (Argentina y Perú), condición de la propiedad (Perú) y conectividad en sus márgenes con Chile para afianzar la seguridad (Argentina). En el caso de Bolivia operan activa y preocupantemente el contrabando, así como una deliberada, sostenida y cada vez más agresiva política exterior-impulsada por la disputa respecto de la reivindicación marítima- que posiciona una demanda territorial en un espacio equipado que se desconoce como tal, hecho que es escasamente percibido desde el centro de gobierno nacional, que insiste en una mirada Santiago/La Paz.

Las estrategias para el establecimiento de un desarrollo territorial inclusivo, al contrastarse con los aportes regionales-nacionales versus las experiencias comparadas en América Latina sobre la materia, han arrojado que uno de los grandes problemas de las fronteras en América Latina lo constituye la superposición de agendas tradicional y de nuevas amenazas a la seguridad. En la disputa de agendas prima la desconfianza, y la nueva agenda de seguridad que, por su carácter transnacional, requiere de la articulación y cooperación interestatal.

$\mathrm{Al}$ analizar las principales transformaciones y problemáticas de las regiones de frontera se observa que las dinámicas cuestionan la idea de fronteras como límites territoriales y de soberanías estatales de carácter rígido. En efecto, las fronteras son cada vez más porosas, constituyendo un espacio donde convergen diversos actores y procesos sociales. Sin embargo, esto no supone la desaparición de las fronteras o la retirada del control estatal en dichos territorios. Por el contrario, su administración sigue siendo una de las tareas del Estado. Así, la dimensión territorial mantiene su importancia, lo que se advierte es la necesidad de un cambio en las funciones del control estatal y las formas de territorialización.

En el caso de los territorios correspondientes a la frontera norte y sur de Chile, estos constituyen frontera interna e internacional a la vez. En su condición de frontera interna, históricamente se han caracterizado por su aislamiento y marginalidad, "zona extrema" y "localidad aislada", calificativos que se han usado desde la institucionalidad estatal para designarlas. Como frontera internacional, las dinámicas económicas y sociales en el marco de la globalización han generado una inusitada importancia de esta zona como pivote para el desarrollo y la integración en torno a tres variables: comercio y exportación de bienes primarios, infraestructura y seguridad. Respecto del proceso de internacionalización, cabe indicar que a la fecha no existe un diagnóstico conocido del estado de situación que permita identificar en qué etapa se está actualmente en el proceso de internacionalización de las regiones de Chile. Al respecto la Dirección de Coordinación Regional del Ministerio de Relaciones Exteriores posee escasa presencia regional. Asimismo, se observa que los mecanismos de inserción internacional que desarrollan las regiones de manera autónoma, no necesariamente responden a una política transversal de internacionalización de Chile.

Hoy existen espacios de territorio nacional que están inmersos en conflictos que afectan sus intereses, con amenazas difíciles de identificar. La lucha por el control territorial de las zonas extremas y por influenciar en diversos ámbitos de la cotidianeidad, pugnan culturalmente con la visión andina de dominio territorial de los vecinos Perú y Bolivia. Esto es diferente en el espacio meridional del país. Por ello, el monitoreo de los conflictos con Perú y Bolivia, especialmente, requiere de miradas cruzadas, donde la defensa y la seguridad constituyen dimensiones paralelas a la institucionalidad y el modelo de desarrollo. 
Esta investigación concluye que la hipótesis de conflicto en el marco de la defensa, no es una amenaza. El peligro para sus poblaciones, la gobernabilidad, la probidad institucional, el desarrollo y la seguridad están en directa relación con la evolución del narcotráfico, el contrabando, y la migración irregular que encuentran en Perú y en Bolivia escaso y casi nulo control en las fronteras con Chile. En ese contexto, el Estado chileno debe mirar integralmente.

\section{Agradecimientos}

Se reconocen y agradecen la colaboración de la licenciada Bárbara Rodríguez González y los financiamientos entregados por el Consejo Nacional de Ciencia y Tecnología y la Academia Nacional de Estudios Políticos y Estratégicos. Investigación FONDECYT 1120405 y PROYECTO ANEPE 201506.

\section{Literatura Citada}

Aroca, P.; Soza-Amigo, S.

2013. Diferencias productivas estructurales entre el centro y la periferia: Magallanes y Arica versus el promedio nacional. Magallania [online], 41 (2), 101-118. ISSN 0718-2244.

Correa, L.

2013. Políticas públicas y gobernabilidad en las zonas extremas de Chile, 2010-2012. Revista de Estudios de Seguridad y Defensa (ESD), $\mathrm{N}^{\circ} 1$. http://esd.anepe.cl/wp-content/ uploads/2013/10/Libro_ESD_web.pdf

Correa, L.; Soza-Amigo, S.

2014. Regiones extremas y su invisibilidad en Chile. En Revista Si somos americanos, 14 (2): 187-216.

García, V.

2014. En los confines del Estado. Una mirada comparada a la seguridad en las zonas fronterizas de Sudamérica, en
Zavaleta, José Alfredo (Coordinador). El laberinto de la inseguridad ciudadana. Bandas criminales, seguridad de fronteras y regímenes penitenciarios en América Latina. Buenos Aires: CLACSO. Pp. 227-255. ISBN 978-987-722-016-2.

Salas, A.; Correa, L.

2013. Diagnóstico crítico de los mecanismos de cooperación internacional en América Latina para la seguridad. En $\mathrm{La}$ Seguridad Nacional Integral en México. Diagnósticos y Propuestas. Centro de Estudios Superiores Navales. México, ISBN 978-607-8148-04-2

Soza-Amigo, S.; Aroca, P.

2012. Análisis y simulaciones en base a las matrices insumoproducto de la comuna de Punta Arenas para los años 2003 y 2007. Magallania, 40 (2): 113-127. 
